\title{
TOILET TRAINING IN AOTEAROA NEW ZEALAND: THE USE OF CRITICAL, QUALITY AND PURCHASED TIME
}

\author{
Rita Robinson, ${ }^{1}$ Clare Hocking ${ }^{2} \&$ Deborah Payne ${ }^{3}$
}

\begin{abstract}
The socialisation of a child into society's ways of managing body wastes is an important life skill that can impact the physical and mental health of the child and the public health of the child's community. It is our argument that the discursive practices of 'in the moment time' of toilet training are as yet under-considered. We raise questions around the loaded expectations placed on those adults supporting the orchestration and learning of this task, particularly mothers. Using a Foucauldian discourse analysis, we identified three constructions of toilet training time: purchasing time, quality time and critical time. Our findings showcase the covert underpinning of medical neurodevelopmental knowledge providing justification for aesthetic and moral practices, as well as locating the subjectivities of a committed mother and, by contrast, a non-committed mother. This analysis opens space to think otherwise about the assumptions underpinning the task of toilet training and the social expectations for how mothers use 'in the moment time' during this task.
\end{abstract}

Keywords: toilet training; Foucault; discourses; mothers; time

\section{INTRODUCTION}

Being socialised into society's ways of managing body wastes is an important life skill which has the potential to impact the physical and mental health of the child and the public health of the child's community (Black and Fawcett 2008; Kovacic et al. 2015). This process of learning is often called toilet training. We define toilet training as a process in which a child learns to independently manage their excretory functions in a way that fits with society's norms. Toilet training is an important aspect of public health by ensuring that appropriate use of sanitation systems occurs. The connection between sanitation and health has a prominent place on the world stage (Black and Fawcett 2008; 
UNICEF 2012), however, the people charged with teaching toileting and the discourses which shape how this is carried out are often not acknowledged.

Literature on how to toilet train children is vast, within both scholarly journals and popular media forums. This literature tends to focus on how to toilet train (Vermandel et al. 2008), comparing toilet training methods and outcomes (Duffin 2012; Kaerts et al. 2012), particularly constipation and incontinence issues (Kovacic et al. 2015) and a concern with cross contamination in early education facilities (Hoque et al. 2003), all which reflect the prominence of medical discourses. With all that is published, consideration of the productive nature of this advice on adults' use of time, particularly mothers, and how this constructs subjectivities, has not yet attracted much academic attention. Mothers' use of time, particularly 'in the moment time', captures the notion of the hidden tasks and expectations required during the act of toilet training. We propose that these expectations are often framed as being morally and aesthetically correct practices to engage in, however, when unpacked, we demonstrate that they are underpinned by powerful medical discourses. Exposing the interplay between moral, aesthetic and medical practices is important because practices underpinned by moral and medical knowledge are often produced as taken-for-granted truths and therefore seen as natural and unchangeable. Locating the practices and subjectivities produced by the interplay of medical, moral and aesthetic discourses enables space to think otherwise and potentially challenge taken-for-granted truths, such as the gendered nature of toilet training, the societal importance we place on independent toileting and the dominating power of medical discourses. Lastly, we argue that toilet training, due to its connection with these discourses, is produced as a key juncture that the mother, in particular, is expected to navigate correctly to ensure a positive life course forward for her child.

This article completes a three-part genealogy of toilet training practice. Firstly, Toilet Training Discourses in 1950 s Aotearoa New Zealand (Robinson, Hocking, and Payne 2016b) showcased the influence of medical and psychoanalytical discourses on the everyday practices of mothers and children, while the second article, Toilet Training Practice and Subjectivities in 1980 s Aotearoa New Zealand (Robinson, Hocking, and Payne 2016a) demonstrated how a shift in toilet training practice was influenced by the contextual situation of neoliberal and human capital discourses. The present article provides the final part of the toilet training story by describing current-day practices and subjectivities.

This article is structured in the following manner. First, we outline the methods and texts used to support his inquiry. Within this process, we present the 
relevance of time as a concept of inquiry for toilet training. We then review discourses and practices from the 1950 s and 1980s, and expand these to consider how these discourses have transformed (Nicholls 2009) and present themselves in the contemporary context as distinctive time use requirements. Following this, we discuss the consideration of toilet training as a key juncture requiring navigation by the mothers. We conclude the article by problematising societal assumptions underpinning the task of toilet training and how mothers are expected to use the time needed to accomplish this task.

\section{METHOD}

This article reflects the thinking of Michel Foucault (1972, 1977, 1988, 1990), who demonstrated that normative truths emerge from what is understood as legitimate knowledge. This knowledge is disseminated through discourses, which in turn produce ways of thinking, doing and categorising people. Therefore, following Foucault's scholarship, a coupling between knowledge and power exists, and shapes society's everyday experiences. This inquiry particularly considers discourse and practices stemming from a medical, aesthetic and moral knowledge, and how they shape time use, particularly toilet training time. Moral discourses relating to excretory practices are those tasks used to manage actions that repulse society (Inglis 2001). We expand consideration of this repulsion to include taken-for-granted truths of the correct thing to do with regard to care of oneself, others and the environment (Ritchie et al. 2010). Medical discourse relates to the health and development of the body as well as public health, while aesthetic discourses are based in people's sensory responses to bodily excreta (Inglis 2001) and everyday responses to sensory experiences. Similar to medically produced discursive actions (actions produced from discourses), people's moral and aesthetic reactions to excretory practices are socially constructed and can therefore be brought to light and then traced to their sociocultural sources (Rose 1996).

Foucault's thinking highlights how knowledge/power are influenced by their historical cultural context (Foucault 1972, 1977), and therefore discourses and the texts are firstly considered against their situated context, and then secondly, compared against other time periods to highlight how knowledge and practice have changed. This type of discourse analysis is called a genealogy. Social discourses have produced toilet training as a sanitation and public health issue and therefore this inquiry also takes on a biopolitical focus. Additionally, considering how people can construct their own lifestyles within the boundaries of acceptable practices, such as engaging in a type of mothering that uses elimination communication, a governmental focus is also relevant. 
A governmental focus considers the interplay between normalised practices shaped by surveillance and engaged in by the collective population and individualised practices. These practices may be personally chosen to strive to match the norm or separate oneself from the norm, the main difference being self-surveillance versus collective surveillance holding practices in place (Foucault 1977, 1988). Therefore, this article has the strongest methodological bent towards being governmental, particularly a mother's supposed freedom to shape her own actions in regard to how she engages in toilet training her child.

It is important to note that Foucault was a poststructural thinker, meaning that he rejected the premise that there are objective truths. Accordingly, in the discourses and subjectivities highlighted in this inquiry, other equally valid perspectives are also circulating. With this openness to multiple perspectives and truths being acknowledged, the credibility of this inquiry is supported by evidence from present-day magazines, blogs (Chatel 2015; Keith 2014), websites (Huggies 2016b; Meads 2016), manuals (Ministry of Health 2002) and newspaper articles (Chug 2013; Grade 2013) as well as documents at governance levels (New Zealand Government 2016) that support our argument that statements and advice on toilet training reflect discourses, technologies and subjectivities in play within current contexts.

\section{Theorising time in toilet training}

We began by reading broadly across a range of toilet training literature. We noticed an association between toilet training and time, and the ways in which constructions of time influenced the everyday practices of adults and children. Time is a disciplinary mechanism Foucault (1977) discusses in Discipline and Punish. This concept stood out as a technique worth further exploration, and therefore provided the theoretical focus of this article. The most obvious connection to time was how time frames are used to explain and measure a child's expected progression along the continuum of instinctual body waste voiding, to controlled body waste voiding. It is these behavioural time frames that cause the concept of time to be repeatedly included in texts about toilet training, particularly when to start, and how frequently to take a child to the toilet. Community-level texts, such as Huggies' website (2016b), Well Child Tamariki Ora: My Health Book (Ministry of Health 2002), and The Tricky Bits. Tips for Under-Fives [S.K.I.P] all inferred or provided a time in which toilet training should be considered. Another construction of time use that we identified refers to the misuse of time as demonstrated by Grade (2013): 'The average child goes through 6,000 disposable nappies [diapers] from the time they are born until they are toilet trained' (p. 9). Grade's use of the word time illustrates 
the more subtle but dominant connection between time and the process of toilet training. Time is seen as a precious resource; therefore, if toilet training is started before children are deemed developmentally ready, parents are seen as wasting time trying to toilet train too early. In contrast, if parents start after readiness has occurred, they are also seen as wasting the time spent changing children who could have been independently toileting themselves. These constructions reflect the notion of misused time and allude to the idea that there is a correct time to toilet train.

What is also included in analysed texts like those cited above, often as a normative practice was how adults are expected to use time during toileting to socialise with children. The process through which children acquire cultural knowledge has been a long-standing area of inquiry. Over the course of history, the view of childhood has changed, from children being mini-adults in smaller bodies, to infancy unfolding into adulthood in a predictable pattern due to innate biological structures, to a passive blank slate to fill up and shape through operant conditioning, to, in more modern times, that of an active agent who interprets, engages and shapes their experiences and holds agency (James and Prout 2015; Woodhead 2006). These shifts in thinking reflect the changing nature of knowledge and what is deemed to be true at that point of history (Foucault 1990). Current thinking reflects a sociocultural and ecological view of children's development and therefore acknowledges the processes of enculturation and socialisation. This focus in turn prompts the consideration of the roles of parents and others in a child's ongoing development. How toileting time is used, and who is expected to dedicate 'in the moment time' with a child during the task of toilet training reflects society's normative expectations of who is responsible for the socialisation of children. Therefore, although acknowledging the child's agency in toilet training, this article focuses on the discourses that shape the adults engaged in the task of toilet training children, particularly mothers. The connection between time, toilet training and mothers being responsible for this task seemed to be a taken-for-granted and obvious truth, and therefore to unsettle these discourses we utilised additional Foucauldian tools.

Following Foucault's rule of exclusion, which refers to that which is prohibited, that which is mad and that which seems false (Hook 2001), we started examining community-level sources, such as newspapers and magazines, for toilet training practices that might be considered alternative or marginal within Aotearoa New Zealand. This process helps to unsettle the taken-for-granted truths that connect toilet training to the medical model. We found texts on a practice termed 'elimination communication' (Bauer 2016; Chug 2013; Grade 
2013; Walker 2014). Applying discourse analyses, we compared elimination communication statements with normalised practices published in texts by the Ministry of Social Development (S.K.I.P 2011) and the Ministry of Health (2002). Normalised in this context means that which has been researched under a medical developmental lens and then espoused as the expected behaviour (Ewald 1990; O'Farrell 2005). The analysed statements were then traced to everyday practices, illustrating ways in which the structuring of time and subjectivities are produced. In this article 'doing', practice and discursive practice are interchangeable terms referring to everyday actions.

Although for Foucault, knowledge and history should not be viewed as progressive (O'Farrell 2005), he did acknowledge the layering of knowledge through the process of commentary (McHoul and Grace 1998) and therefore transformation of discourses and practices (Nicholls 2009). Therefore, we begin with a brief review of toilet training practices in Aotearoa New Zealand since the 1900s.

HISTORICAL OVERVIEW AND THE EMERGENCE OF CRITICAL TIME DISCOURSES

Normative toilet training practices in early 1900 s Aotearoa New Zealand were established by Truby King, the founder of the Royal New Zealand Society for the Health of Women and Children (Inc), later referred to as Plunket. Plunket's mission was to 'help mothers and save babies' (Deem and Fitzgibbon 1948). In the early 1900 , high rates of infant deaths were a national concern. King's solution to this problem was to draw on medical hygiene knowledge and utilise behavioural conditioning to improve the health of young New Zealanders by teaching mothers scientifically espoused ways of mothering (Bryder 2003). These influences were reflected in the toileting advice given by Plunket. From the early 1900 s to the 1950 s, children as young as three weeks of age were placed on a small chamber pot at regular time-measured intervals to produce a bowel motion on cue. This practice, often supported by a diet of prunes and the administration of enemas, was seen as morally appropriate to ensure the future discipline and physical health of the child (Deem and Fitzgibbon 1948). Improving the health and increasing the numbers of European babies was considered critical to the effort of colonising New Zealand, and one that was primarily the mother's responsibility (Bryder 2003).

In the 1950s, informed by neuroscience, developmental psychology and psychoanalytical discourses, a shift in toilet training practices occurred (Robinson, Hocking, and Payne 2016b). The toilet training of children moved to a later age, 
justified by the finding that the myelination of the cortical nerve tracks from the bladder to the brain were not in place until after eighteen months of age (Ford 1952). Thus, it was argued that children do not have the physiological capacity to exercise control over waste excretions until myelination is complete. Lists of observable readiness skills demonstrated by the child during this time frame, such as putting items away, enabled mothers and child development experts to gauge when this internal development had occurred (Spock 1946). This normalising knowledge led to child development being described in grids of specification, showcasing stages of development, each stage assigned to an age and mapped against a time continuum. These published time frames, although developed in the 1930s (Gesell 1948), became readily accessible during the 1950 s via medical textbooks and parenting books (Beatty, Cahan, and Grant 2006), specifically in Aotearoa New Zealand in Spock's Baby and Child Care (1957) and Deem and Fitzgibbon's Modern Mothercraft (1953).

Ways of thinking about child development were also influenced by psychoanalytical discourses because of the perceived need to address children's emotional health. Although the physical health of New Zealand children had improved over the previous fifty years, in the eyes of those who ascribed to psychoanalytical theory, Aotearoa New Zealand's way of raising children was theoretically uninformed (Bevan-Brown 1950). As mothers were constructed as the primary caregivers during this historical period, discourses broadening the gaze beyond children's physical health positioned mothers as also being responsible for their child's emotional development (Robinson, Hocking, and Payne 2016b).

Many factors shaped this construction of mothers' roles and responsibilities, including Bowlby's Maternal Care and Mental Health Deprivation Report (Bowlby 1951) to the World Health Organisation (Kedgley 1996). The knowledge informing this report came from theories connecting mothering, toilet training, excretory functions and personality development together, such as the anal stage in Freud's psychosexual theory, and autonomy versus shame and doubt in Erikson's psychosocial theory (Erikson 1950; Weiten 2014). According to these two theories, teaching and responding correctly to the management of excretory body functions is a catalyst that can influence people's emotional health in adulthood (Erikson 1950; Stallworthy 1959). Therefore, the mother's ability to facilitate excretory management correctly and within the proposed time frames, was critical to the ongoing emotional and physical success of the child. These psychoanalytical discourses altered this everyday task, enabling child-centred rather than mother-led toileting practices to emerge. Psychoanalytical knowledge thus piggybacked on the quantitative, empirically based ages and stages grids of specification, reinforcing the practice of conducting 
toilet training in the child's second year of life. Thus, the second year of a child's life was constructed as a critical time for mothers to start toilet training, with this obvious truth produced through the knowledge sources of medical science, neuroscience, developmental psychology and psychoanalytical theory securing medical discourses prominence in shaping toilet training practices and a mother's role within it (Robinson, Hocking, and Payne 2016b). These constructions, the initiation of training and mothers being responsible for this task, continued through authoritative commentary into the $198 \mathrm{os}$ and present day (Robinson, Hocking, and Payne 2016a). In the following section, we demonstrate that in the 198 os mothers are still positioned to be the lead adult involved in toilet training, but for new reasons and in new ways.

\section{A new strand to critical time}

In the 1950s, it was considered critical to complete toilet training within a specific time frame, in a particular way (Robinson, Hocking, and Payne, 2016b). In the 2010 s these discourses remain; however, they have been transformed to also consider the critical nature of how society uses resources and how this affects the health and the aesthetics of people and the earth. Acting in an earthwise, responsible manner and instilling this way of thinking in children are increasingly seen as ethically important and therefore critical (Dombroski 2013; Lee 2013; Ritchie et al. 2010). One way of instilling this thinking occurs through the products and processes used to support toilet training. We suggest that sustainability practices and medical discourses of critical time are woven together in contemporary understandings influencing in the moment time' use.

From the 1980 os to current day, practices emerging from medical and aesthetic discourses have contributed to the production of sustainable toilet training practices. Starting in the 198 os with conversations around cloth diapers versus disposable, sustainability discourses have shaped toilet training practices and in turn have been created as a marker of a type of chosen lifestyle, as indicated by commentators such as Keith (2014) in saying, 'There's nothing wrong with cloth diapers, but once they're elevated from something that catches a baby's poo into a lifestyle, something has gone awry' (p. 99). The implication here is that cloth nappies are an ethical choice used to signify a green lifestyle. This connection between parenting and sustainability practices is illustrated in this quote taken from a New Zealand-based website Thenappylady.co.nz: 'We started with nappies [choosing cloth not disposables] and went from there. Over time we added in one little step at a time and have become a sustainable household' (Meads 2016, para 1). 
Toilet training offers the opportunity to model sustainability practices and values through the products chosen or rejected. Mothers are actively constructing not just cultural knowledge about toileting expectations, but also sustainability knowledge (Dombroski 2013). Decreasing the number of nappies in landfills and in turn stopping the leaking of body wastes into potable water sources, as well as the health of children's skin are motivating factors (Baer, Davies, and Easterbrook 2006). Another motivation for sustainable toilet training practices is the aesthetics created through these practices, bonding with a child through elimination communication, not having to change nappies, or, for the child, the aesthetics of not having body wastes trapped next to the skin. The elimination of discarded nappies in public places and landfills is also considered an aesthetic factor (Lee 2014). The push to alter the use of disposables has lead thirty district councils in New Zealand to contract a cloth nappy educator 'to explain the advantages of the reusables to expectant parents, in an effort to cut down on domestic waste' (Akoorie 2014, para 4). The following quote demonstrates this connection between saving time and damaging the environment: 'We were convinced by very astute marketing that we would have more time available in our lives if we used disposable products because you could just throw it away when you are done with it instead of taking the time to wash it' (Meads 2016, para 3). Mothers who are committed to the earth, will not mind taking extra time to change and wash cloth nappies for the health of the planet.

\section{QUALITY TIME}

In this section, we highlight the discourses and practices located in the 1980s relating to toilet training, extending the genealogical analysis presented by Robinson, Hocking, and Payne (2016a). Then we demonstrate how these discourses and practices are being transformed through current-day commentary. In the $198 \mathrm{os}$, the timetable for initiating toilet training continued to be around two years of age, demonstrating that the discursive construct of critical time from the 1950 s was still in play. However, new knowledge broadened the task of toilet training into a valid opportunity to cognitively enrich a child's early learning skills and, therefore, human capital. Human capital is seen as the potential to economically capitalise on each person, to make the most, or get the most out of them as a citizen. Improving children's cognitive skills improves their learning power, which in turn improves their earning potential as an adult (Stuart 2011).

In the 1980s, an overlap of psychoanalytical theory, which stressed the importance of the mother-child relationship during toilet training, merged with human capital discourses, which placed increased value on cognitive devel- 
opment (Robinson, Hocking, and Payne 2016a; Stuart 2011). These combined discursive constructs created the emergence of 'quality time.' The construct of quality time reinforced intensive mothering practices, these practices being 'child-centred, expert guided, emotionally absorbing, labour intensive, and financially expensive' (Hays 1996, 122). Intensive mothering assumes that the mothers should be primarily responsible. Furthermore, they 'are expected to see the world through the eyes of the child, and thus respond always from that subject position' (Arnold 2014, 47). In this way, intensive mothering knowledge shapes a mother's and child's engagement in everyday tasks in a very specific way. Quality engagement became seen as a morally correct way for mothers to parent their child. However, even the normative discursive construct of quality contains acts of resistance. Unpacking these degrees of quality is important because this exposes discourses and the construction of differing subjectivities produced, particularly that it is mothers who are the ones responsible for their child's development.

\section{Mothers of now}

Walker (2014) describes a subset of mothers to be an 'extreme form of intensive mothers' (p. 60). They ascribe to the toilet training practice of elimination communication (Walker 2014), which involves observing and then responding immediately to the signs of an infant's impending bowel or bladder release by holding them over the toilet while pairing a vocal or hand signal to the child (Bauer 2016). The pairing up of a signal with the act of toileting is intended to establish a classical conditioning response. This is very similar to the holding out of children in the early 190os, except that the mother is responding to an infant's signal rather than a prescribed timetabled routine set by Plunket. Engagement in intensive practice of elimination communication is seen as an opportunity to enrich quality time between mother and child to an even deeper level as demonstrated by this quote: 'The greatest reason and benefit, however, is that parents feel they are responding to their baby's needs in the present moment, enhancing their bond, and developing a deeper communication and trust' (Bauer 2016, para 5). Therefore, quality time is seen as having a specific aesthetic quality attached to it, while, at the same time, including the traditional and medically based practice of bonding and, therefore, attachment (Schore 2000).

\section{Maximising time, reading with toilet training}

Another quality-time practice that shapes 'in the moment time' is reading to children. Reading to children about toilet training before, during or after the 
task has been advocated since the 1980s (Ritchie 1978; S.K.I.P 2011; Welford 1987). A specifically created genre of children's books depicting everyday activities, such as toilet training, embraced a child-centred view, informed by learning theory and human capital influences emerged during the $1980 \mathrm{os}$ (Robinson, Hocking, and Payne 2016a). Contemporary books of this genre are adorned with technology of simple cause-and-effect buttons, providing auditory additions of toilets flushing or people cheering to the reading experience (Pinnington 2009) or are tactilely rich with padded toilet seats incorporated on the cover (cognitive enrichments) (Sirett 2010). These additional adornments reflect practices arising from aesthetic discourses to enrich the sensory experience of reading and from a human capital perspective, the cognitive stimulation of the child.

Reading to children about the steps of toilet training and mastery of toileting experiences is seen as a way to regulate action, to strengthen the relationship between mother and child, while also enriching sensory, language and early academic understanding. The location of this task is in the bathroom, while sitting on a toilet, as demonstrated by Chatel (2015) when she says, 'By 15 months old, he was sitting on the toilet by himself - one hand on the side of the seat and the other between his legs - as I [...] read him a book' (para 1).

This connection of reading and toilet time was such a taken-for-granted truth in Aotearoa New Zealand that, in 2013, Treasures nappies adorned their products with characters from the Hairy McClary children's book series. Huggies, another provider of disposable diapers, also suggests reading and even has a children's book club (Huggies 2013, 2016a, 2016b). Even Strategies with Kids/ Informing Parents (S.K.I.P), a resource published by the Ministry of Social Development, states 'read books or tell some stories about kids learning to use the toilet' $(2011,4)$. A mother engaging with her child in this manner has ascribed to the obvious truth that good mothers enrich their child at any opportunity, and do this in a manner consistent with societal norms of what constitutes quality time.

The connection between books within a home and future success is well documented (National Library of New Zealand n.d). Following this line of reasoning, parents who invest in reading products for their children will improve their child's educational outcomes and therefore invest in their child's future, giving them the edge to success in society (Nadesan 2002). A popular parenting magazine demonstrates the link between quality time, reading and future success: 'A cuddle, your voice and something to look at [book] - it's all starting them off on their road to a PhD ...' (Cowan 2016, 35). Milkie and Warner 
(2014) described this practice as status safeguarding. The ultimate goal of status safeguarding is to ensure that their child reaches the highest social status achievable. This 'entails vigorously pursuing what is believed to be the best for an individual child at every key juncture through anticipating and solving status problems' (Milkie and Warner 2014, 68). This connection between status safeguarding and toilet training as a key juncture is what we now consider.

\section{Toilet training - a key juncture}

We propose that toilet training has become one of these key junctures, which is possibly why mastery in this task is loaded with assumptions regarding the future trajectory of the child and why 'in the moment time' is so heavily constructed by society. Many of these assumptions stem from child development theories put in place during the 1950 os and 1980s, linking critical time and quality time discourses with toilet training. Quality time, which is influenced by medical and aesthetic discourses, can be a form of status safeguarding, and is further enriched by purchasing educational products (Nadesan 2002: Takseva 2014). Financial security also influences the ability to invest in quality time, as it affords more freedom to make choices about toilet training practices (Appling 2012). Choices include purchasing products and leads us to consider a mother's engagement in the paid workforce and the utilisation of early childhood education services.

\section{PURCHASING CHILDCARE}

To be a mother and return to the workforce full or part-time before one's child starts to attend school requires someone to look after the child. While this could be the child's other parent or kin, in Aotearoa New Zealand this service is predominantly provided by early childhood education organisations (Carrol-Lind and Angus 2011; Ministry of Education [MoE] 2016). Parents are in effect purchasing childcare and the attendant daily practices associated with the socialisation of young children. Huggies, a diaper producer, specifically suggests engaging another person to assist with the toilet training process 'if you simply can't afford time off work or you find yourself as busy as a bee, perhaps looking for a babysitter or carer is another option' (n.d, para 5). This statement clearly articulates that 'in the moment time' toilet training is ideally performed by parents. It also illustrates how this time is a commodity that, grudgingly, is allowed to be outsourced in the case of toilet training.

Growth in the enrolment of children in early education services is the result of changing perceptions of the value of education and the value of influences 
from outside the family (Levy 2016; May 2013). This practice is reinforced by government policies that enable parents to enrol children in daycare or early education from three months of age for a cost, and for children three to five years of age, free for twenty hours a week and a maximum of six hours a day (New Zealand Government 2016). Consequently, the task of toilet training may be conducted outside the home by adults not biologically connected to the child (Kaerts et al. 2012; MoE 2016). These structural changes influence the aesthetic experiences of children learning to be toilet trained, and the mothers who now frequently share this task with other adults who may be unfamiliar with their family's ways of doing and, additionally, are constrained by health and safety protocols in the childcare workplace.

\section{Committed subjectivities}

The government is committed to young children having a good start to their educational life (Ministry of Health 2016) and therefore supports the qualification and employment of trained early childhood teachers. However, commentary which transforms discourses from the 1950s and 1980s ignores this contextual shift, and continues to produce the taken-for-granted truth that it is primarily mothers who choose and purchase products at critical times to support their child's development at this key life course juncture. In this way, committing 'in the moment time' to a developing child is constructed as the morally correct thing for a mother to do.

Toilet training takes commitment, whether by using elimination communication (Chug 2013) or mainstream toilet training practices (S.K.I.P 2011). Therefore, when mothers engage in this task, they are able to take up the subjectivity of being a committed mother. The implication is that mothers who delay toilet training their child because they are unable to commit to the time required to complete the task (Daily Mail 2017) are not committed mothers. This might be an act of resistance to the normalising truths of toilet training discourses, but can also be construed as deviance, inviting moral judgement, 'How can a mother be too idle to potty-train her child' (Parson 2012, para. 1). The above quote reinforces the discourse that mothers are the parent primarily responsible for toilet training, and that failure to toilet train in accordance with dominant discourses on the topic is a moral issue.

TRANSFORMATION AND THE COMPLEXITY OF SUBJECTIVITIES

We proposed that toilet training advice has created heavily loaded 'in the moment time' expectations and discursive actions for both the mother and the 
child engaged in the task. We have described these discursive actions as critical, quality and purchasing time, and have traced their production back to medical, aesthetic and moral discourses. Critical toilet training time is seen as a way to enable physical, emotional and cognitive development. Critical time links back to earlier medical psychoanalytical and developmental psychology knowledge creation linking the mother and the child together. This past knowledge is now justified by new technologies, such as functional magnetic imaging which demonstrates how enrichment and relationship build neural pathways within the brain (Sivaratnam et al. 2015; Swain et al. 2007).

In exhorting adults, through the truth of medical scientific technologies, to make the most of these critical times, an adult, usually the mother, must also engage in quality time. Quality time occurs through the promotion of relationship and learning during these critical times. Quality time also links back to knowledge creation stemming from a psychoanalytical perspective and is once again justified by the neuronal growth espoused in medical discourses (Schore 2000). Enrichment of quality-time experiences is achieved through purchased products (Nadesan 2002), particularly books, adding to the aesthetic quality of the 'in moment time.' Using Foucault's principle of exclusion and the example of elimination communication, we have unsettled normative practices that assume the mother is the parent responsible for her child's development, even though other discourses have constructed space for mothers to engage in paid employment and therefore enable equal opportunity for partners, fathers or others delegated the care of their child to also be equally responsible for the development of the child.

Dominant discourses and normative practices have constructed an ideal committed mother as the one who engages in toilet training at the critical moment, in a quality time way with the support of purchased products, and if engaging in sustainability practices, as one also committed to the earth. This discourse of the committed mother also constructs its alternative - the non-committed mother who has purchased the time of another adult to navigate her child through this key juncture, irrespective of it still being done at the critical moment, in a quality way, while reinforcing sustainable choices. 'In the moment time' during toilet training emerges from a study of contemporary discourses on toilet training as the key axis of articulation between subjectivities of committed and non-committed mothers.

\section{CONCLUSION}

We have argued that to take up all these discursive practices during in the 
moment time' of toilet training creates the subjectivity of a committed mother. However, if the socialisation of toilet training is outsourced to another adult, the subjectivity of a non-committed mother is created. We have argued that, although conceptual space is produced for aesthetic and moral discourses to be acknowledged within the constructions of critical, quality and purchased time, their taken-for-granted truth is intertwined with their underlying connection to medical (public health and neurodevelopmental) discourses. This analysis has created an opportunity to think otherwise about the assumptions underpinning who is expected to conduct toilet training, how and why the 'in the moment time' of toilet training is so heavily constructed towards the mother completing this task, and how this influences the experiences of the child and adults engaged in this civilising task.

\section{NOTES}

1 Rita Robinson is a doctoral candidate with a special interest in childhood studies, occupational therapy and occupational science.

Email: rita.robinson.ot@gmail.com

2 Professor Clare Hocking is well published in the fields of occupational science and occupational therapy. She serves as the Executive Editor of the Journal of Occupational Science.

Email: clare.hocking@aut.ac.nz

3 Associate Professor Deborah Payne is a Director of the Centre for Midwifery and Women's Health Research. With a special interest in disability and health, and also assisted reproductive technologies. Her methodological expertise is in the use of Michel Foucault's concepts.

Email: dpayne@aut.ac.nz

\section{REFERENCES}

Akoorie, Natalie. 2014, 24 March. 'Mums Sold on Modern Cloth Nappies'. New Zealand Herald. Accessed 23 October 2017 from http://www.nzherald.co.nz/ lifestyle/news/article.cfm?c_id=6\&objectid=11224950

Appling, Matt. 2012. 'Rich White Suburban Mom'. The Church of No People. Accessed 23 October 2017 from http://www.thechurchofnopeople. com/2012/05/rich-white-suburban-mom/ 
Arnold, Lorin Basden. 2014. 'I Don't Know Where I End and You Begin: Challenging Boundaries of the Self and Intensive Mothering. In Intensive Mothering: The Cultural Contradictions of Modern Motherhood, edited by Linda R. Ennis, 47-65. Toronto: Demeter Press.

Baer, Erica, Mark Davies, and Kirsty Easterbrook. 2006. 'Disposable Nappies for Preventing Napkin Dermatitis in Infants'. Cochrane Database of Systematic Reviews 3, doi: http://dx.doi.org/10.1002/14651858.CDoo4262.pub2.

Bauer, Ingrid. 2016. 'Diaper Free! The Gentle Wisdom of Natural Infant Hygiene. The Natural Child Project'. Accessed 23 October 2017 from http://www.naturalchild.org/guest/ingrid_bauer.html

Beatty, Barbara, Emily Cahan, and Julia Grant. 2006. When Science Encounters the Child: Education, Parenting, and Child Welfare in 2oth-Century America. New York, NY: Teachers College Pr.

Bevan-Brown, Charles Maurice. 1950. The Sources of Love and Fear. Christchurch, NZ: Raven Press.

Black, Maggie, and Ben Fawcett. 2008. The Last Taboo: Opening the Door on the Global Sanitation Crisis. London, UK: Earthscan.

Bowlby, John. 1951. Maternal Care and Mental Health. Geneva: World Health Organisation. Retrieved from http://apps.who.int/iris/bitstream/10665/40724/1/ WHO_MONO_2_(part1).pdf

Bryder, Linda. 2003. A Voice for Mothers: The Plunket Society and Infant Welfare, 1907-2000. Auckland, NZ: Auckland University Press.

Carrol-Lind, Janis, and John Angus. 2011. Through Their Lens: An Inquiry into Non-parental Education and Care of Infants and Toddlers. Wellington, NZ: Office of the Children's Commission. Retrieved from http://www.occ.org.nz/ assets/Uploads/Reports/Education/Through-their-lens.pdf

Chatel, Katy. 2015. 'How I Taught My Infant Son to Use an Adult Toilet'. PostEverything Washington Post. Accessed 23 October 2017 from https://www.washingtonpost.com/posteverything/wp/2015/02/19/how-i-taught-my-infant-touse-an-adult-toilet/?utm_term=.90c4f2co9401 
Chug, Kiran. 2013. 'No-Nappy Babies'. Accessed 12 March 2015 from http://www. stuff.co.nz/life-style/parenting/baby/caring-for-baby/8629888/No-nappybabies

Cowan, John. 2016. March/April. 'How to Grow Kids Who Love and Learn'. Family is Everything: Parenting 67:35.

Daily Mail. 2017. June 29. 'The Nine Year-olds Who Still Need Nappies: Britain Faces "potty training crisis" as 70\% of Schools Report Increase in the Number Starting Lessons Who Cannot Use the Toilet'. Accessed 23 October 2017 from http://www.dailymail.co.uk/news/article-4649006/Britain-faces-potty-training-crisis.html\#ixzz4qoSnQ6LY

Deem, Helen, and Nora Fitzgibbon. 1948. Modern Mothercraft: A Guide to Parents. Dunedin, NZ: Royal New Zealand Society for the Health of Women and Children.

Deem, Helen, and Nora Fitzgibbon. 1953. Modern Mothercraft: A Guide to Parents. Dunedin, NZ: Royal New Zealand Society for the Health of Women and Children.

Dombroski, Kelly. 2013. Babies'Bottoms for a Better Earth: Hygiene, Modernities, and Social Change in Northwest China and Australasia (Unpublished doctoral dissertation), University of Canterbury, Christchurch, NZ.

Duffin, Christian. 2013. 'Success of Toilet Training Pilot Leaves More Time for Learning'. Primary Health Care 23 (8): 8-9.

Erikson, Erik. 1950. Childhood and Society. New York, NY: Norton.

Ewald, Francois. 1990. 'Norms, Discipline, and the Law'. Representations 30:138-161.

Foucault, Michel. 1972. The Archaeology of Knowledge. Translated by Sheridan Smith. New York, NY: Pantheon Books.

- 1977. Discipline and Punish: The Birth of Prison. Translated by Sheridan Smith. London, UK: Penguin.

- 1988. 'Technologies of the Self'. In Technologies of the Self: A Seminar with Michel Foucault, edited by Luther Martin, Huck Gutman, and Patrick Hutton, 16-49. Amherst, MA: The University of Massachusetts Press 
- 1990. The History of Sexuality, 1. Translated by R Hurley. Harmondsworth, Middlesex: Penguin.

Ford, Frank. R. 1952. Diseases of the Nervous System in Infancy, Childhood and Adolescence. Springfield: Thomas.

Gesell, Arnold. 1948. Studies in Child Development. New York: Harper.

Grade, Kim. 2013. 'New Trend Encourages Toilet Training from Birth' Newshub. Accessed 23 October 2017 from http://www.newshub.co.nz/entertainment/ new-trend-ecourages-toilet-training-from-birth-2013050616

Hays, Sharon. 1996. The Cultural Contradictions of Motherhood. New Haven, CT: Yale University Press.

Hook, Derek. 2001. 'Discourse, Knowledge, Materiality, History, Foucault and Discourse Analysis'. Theory Psychology 11:521-547.

Hoque, Ekramul, Virginia Hope, Robert Scragg, and Tord Kjellstrom. 2003. 'Children at Risk of Giardiasis in Auckland: A Case-control Analysis'. Epidemiology and Infection 131 (1): 655-662.

Huggies. n.d. 'Nappies'. Accessed 23 October 2017 from https://www.huggies.co.nz/ nappies/pull-ups

- 2013. 'Toilet Training Guide'. Accessed 8 May 2014 from https://www. huggies.co.nz/system/cms/files/files/ooo/ooo/o26/original/huggies-toilettraining-guide.pdf

—. 2016a. 'Toilet Training Books'. Accessed 14 March 2016 from https://www. huggies.co.nz/toddler/toilet-training/tools.

- 2016b. 'When To Start Toilet Training'. Accessed 14 March 2016 from https://www.huggies.co.nz/toddler/toilet-training/when-to-start

Inglis, David. 2001. A Sociological History of Excretory Experience: Defecatory Manners and Toiletry Technologies. New York: Edwin Mellen Press.

James, Allison, and Alan Prout. 2015. Constructing and Reconstructing Childhood: Contemporary Issues in the Sociological Study of Childhood. New York: Routledge Falmer. 
Kaerts, Nore, Guido Van Hal, Alexandra Vermandel, and Jean-Jacques Wyndaele. 2012. 'Toilet Training in Daycare Centers in Flanders, Belgium'. European Journal of Pediatrics 171(6): 955-961.

Kedgley, Sue. 1996. Mum's the Word: The Untold Story of Motherhood in New Zealand. Auckland, NZ: Random House.

Keith, J.J. 2014. Motherhood Smotherhood: Fighting Back Against the Lactivists, Mompetitions, Germophobes, and So Called Experts Who Are Driving Us Crazy. New York: Skyhorse Publishing.

Kovacic, Katja, Manu Sood, Suzanne Mugie, Carlo Di Lorenzo, Samuel Nurko, Nicole Heinz, and Alan Silverman. 2015. 'A Multicenter Study on Childhood Constipation and Fecal Incontinence: Effects on Quality of Life'. Journal of Pediatrics 166:1482-1487.

Lee, Nicholas. 2013. Childhood and Biopolitics Climate Change, Life Processes and Human Futures. Hampshire, UK: Palgrave MacMillan.

Lee, Michelle. 2014, January 28. 'Disposable Nappies: Are They Stinking Up Our Planet?' Australian Science. Accessed 23 October 2017 from www.australianscience.com.au/environmental-science/disposable-nappies-are-theystinking-up-our-planet/

Levy, Diane. 2016. March/April. 'Diane’s Corner'. Family is Everything: Parenting, 67,41 .

May, Helen. 2013. The Discovery of Early Childhood. (2nd ed.). Wellington, NZ: NZCER Press.

McHoul, Alec, and Wendy Grace. 1998. The Foucault Primer: Discourse, Power and the Subject. Melbourne, Australia: University Press.

Meads, Kate. 2016, October 10. 'Waste Free Parenting'. Accessed 23 October 2017 from http://www.thenappylady.co.nz/reusablebaby-nappiesandwipes.html

Milkie, Melissa A., and Catharine H. Warner. 2014. 'Status Safeguarding: Mothers Work to Secure Children's Place in the Social Hierarchy'. In Intensive Mothering: The Cultural Contradictions of Modern Motherhood, edited by Linda R. Ennis, 66-85. Toronto: Demeter Press. 
Ministry of Education. 2016. 'Parents: 2o Hours ECE'. Accessed from http:// parents.education.govt.nz/early-learning/early-childhood-education/20hours-ece-2/

Ministry of Health. 2002. Well Child Tamariki Ora Health Book. Wellington: Ministry of Health.

- 2016. New Zealand Health Strategy: Future Directions. Wellington: Ministry of Health.

Nadesan, Majia. 2002. 'Engineering the Entrepreneurial Infant: Brain Science, Infant Development Toys, and Governmentality'. Cultural Studies 16: 401-432.

National Library of New Zealand Te Puna Matauranga O Aotearoa, n.d. 'Reading for Pleasure'. Accessed 23 October 2017 from http://schools.natlib.govt.nz/ creating-readers/creating-reading-culture/reading-pleasure-door-success

New Zealand Government. 2016. 'Help Paying for Early Education Services'. Accessed 23 October 2017 from https://www.govt.nz/browse/education/helppaying-for-early-childhood-education/

Nicholls, David. 2009. 'Putting Foucault to Work: An approach to the Practical Application of Foucault's Methodological Imperatives'. Aporia 1(1):3-40.

O’Farrell, Clare. 2005. Michel Foucault. Los Angeles, CA: Sage.

Parson, Sandra. 2012, February 15. 'How Can a Mother be Too Idle to Pottytrain Her Child?' Accessed 23 October 2017 from http://www.dailymail.co.uk/debate/article-2097962/How-mother-idle-potty-train-child. html\#ixzz4qoRr8udN

Pinnington, Andrea. 2009. Princess Polly's Potty. Auckland, NZ: Ladybird

Ritchie, Jane B. 1978. Chance to be Equal. Whatamongo Bay, NZ: Cape Catley.

Ritchie, Jenny, Iris Duhn, Cheryl Rau, and Janita Craw. 2010. 'Titiro Whakamuri, Hoki Whakamua. We Are the Future, the Present and the Past: Caring For Self, Others and the Environment in Early Year's Teaching and Learning'. Report for the Teaching and Learning Research Initiative, Retrieved from http:// www.tlri.org.nz/sites/default/files/projects/926o-finalreport.pdf 
Robinson, Rita, Clare Hocking, and Deborah Payne. 2016a. 'Toilet Training Practice and Subjectivities in 1980 os Aotearoa New Zealand [online]'. New Zealand Sociology 31 (1): 49-71.

- 2016b. 'Toilet Training Discourses in 1950s Aotearoa New Zealand'. New Zealand Sociology 31(7): 94-111.

Rose, Nikolas. 1996. Inventing Our Selves: Psychology, Power, and Personhood. Cambridge, UK: Cambridge University Press.

Schore, Alan. 200o. 'Attachment and the Regulation of the Right Brain'. Attachment and Human Development 2: 23-47.

Sirett, Dawn. 2010. Girls' Potty Time. Victoria, Australia: Darlington Kindersley.

Sivaratnam, Carmel, Louise Newman, Bruce Tonge, and Nicole Rinehart. 2015. 'Attachment and Emotion Processing in Children with Autism Spectrum Disorders: Neurobiological, Neuroendocrine, and Neurocognitive Considerations'. Review Journal of Autism and Developmental Disorders 2 (2):222-242.

Spock, Benjamin. 1946. The Common Sense Book of Baby and Child Care. New York: Duell Sloan and Pearce.

- 1957. Baby and Child Care (Cardinal ed.). New York, NY: Pocket Books.

Stallworthy, Kenneth R. 1959. The Facts of Mental Health and Illness. Christchurch: Peryer.

Strategies with Kids/ Information for parents [S.K.I.P] 2011. The Tricky Bits Tips for Under-Fives. Wellington, NZ: Ministry of Social Development.

Stuart, Margaret. 2011. Cradle and All; Rocking the Cradle of Wealth. Human Capital Theory and Early Childhood Education in New Zealand, 1999-2008. PhD Thesis. Auckland University of Technology, NZ. Retrieved from http://aut. researchgateway.ac.nz/handle/10292/4452

Swain, James, Jeffery Lorberbaum, Samet Kose, and Lane Strathearn. 2007. 'Brain Basis of Early Parent-infant Interactions: Psychology, Physiology, and In Vivo Functional Neuroimaging Studies'. Journal of Child Psychology Psychiatry 48:262-287. 
Takseva, Tatjana. 2014. 'How Contemporary Consumerism Shapes Intensive Mothering Practices'. In Intensive mothering: The Cultural Contradictions of Modern Motherhood, edited by Linda R. Ennis, 211-232. Toronto: Demeter Press.

Vermandel, Alexandra, Marijke Van Kampen, Chris Van Gorp, and Jean-Jacques Wyndaele. 2008. 'How to Toilet Train Healthy Children? A Review of the Literature'. Neurourology Urodynamics 27:162-166.

Walker, Madeline. 2014. 'Intensive Mothering, Elimination Communication and the Call To Eden'. In Intensive Mothering: The Cultural Contradictions of Modern Motherhood, edited by Linda R. Ennis, 233-246. Toronto: Demeter Press.

Weiten, Wayne. 2014. Psychology: Themes and Variations (7th ed.). NSW, Australia: Thomson Wadsworth.

Welford, Heather. 1987. Successful Potty Training. London, UK: Thorsons.

Woodhead, Martin. 2006. 'Changing Perspectives on Early Childhood: Theory, Research and Policy'. International Journal of Equity and Innovation in Early Childhood 4(2): 1-43.

UNICEF. 2012. Pneumonia and Diarrhoea: Tackling the Deadliest Diseases for the World's Poorest Children. New York, NY; World Health Organisation 